\title{
Ketahanan Moderasi Beragama Mahasiswa di Tengah Melting Pot Gerakan Keagamaan di Surakarta
}

\author{
The Resilience of Religious Moderation of University Students \\ in the Melting Pot of Religious Movements in Surakarta
}

\begin{tabular}{l|r}
\hline Moh. Ashif Fuadi & \multicolumn{1}{c}{ Article history: } \\
Fakultas Adab dan Bahasa, Universitas Islam Negeri Raden Mas Said & $\begin{array}{r}\text { Submitted: 28 Oktober 2021 } \\
\text { Accepted: 22 November 2021 } \\
\text { Surakarta, Indonesia } \\
\text { moh.ashiffuadi@iain-surakarta.ac.id }\end{array}$ \\
\hline
\end{tabular}

Abstract: Besides being famous as a city that has a rich Javanese cultural heritage, in Surakarta, Central Java, there are also various religious-based views and organizations, ranging from those that can be categorized as the moderate groups to the radical ones. The existence of one of the PTKIN (State Islamic Universities), namely UIN Raden Mas Said in Surakarta, certainly makes it a place for various views to flow. This study discusses the influence of religious background on the religious attitudes of UIN Raden Mas Said students. Through qualitative research methods employing surveys, this study concludes that the large variety of religious organizations in Surakarta does not necessarily affect students' religious understandings and attitudes. In contrast to several previous studies which indicated a relationship between student activities and the puritan fundamentalist movement, this study proves that the students still have a moderate, inclusive, tolerant religious understanding, respect for tradition, and are loyal to the state ideology. Amid the potential for exclusivity as an excess of being in a melting pot of various religious views, students have resilience in maintaining an attitude of religious moderation.

Keywords: PTKIN; religious attitude; religious moderation; student; Surakarta; UIN Raden Mas Said.

Abstrak: Selain populer sebagai kota yang memiliki kekayaan warisan budaya Jawa, di Surakarta Jawa Tengah juga terdapat beragam aliran dan organisasi masyarakat berbasis keagamaan, mulai dari yang dapat dikategorikan moderat hingga radikal. Keberadaan salah satu PTKIN (Perguruan Tinggi Keagamaan Islam Negeri), yakni UIN Raden Mas Said di Surakarta, tentu menjadikannya sebagai tempat bermuaranya berbagai aliran. Penelitian ini membahas pengaruh latar belakang keagamaan terhadap sikap beragama mahasiswa UIN Raden Mas Said. Dengan metode penelitian kualitatif melalui survei, penelitian ini menghasilkan kesimpulan bahwa banyaknya ragam aliran keagamaan yang di Surakarta tidak otomatis memengaruhi pemikiran mahasiswa menjadi radikal. Berbeda dengan beberapa penelitian sebelumnya yang mengindikasikan adanya hubungan antara kegiatan mahasiswa dengan gerakan puritan fundamentalis, penelitian ini membuktikan bahwa mahasiswa masih memiliki pemahaman keagamaan yang moderat, inklusif, toleran, menghargai tradisi, dan setia terhadap ideologi negara. Di tengah potensi eksklusifitas sebagai ekses dari keberadaannya di melting pot ragam aliran, mahasiswa memiliki ketahanan dalam menjaga sikap moderasi beragama.

Kata kunci: mahasiswa; moderasi beragama; PTKIN; sikap beragama; Surakarta; UIN Raden Mas Said.

P-ISSN 1907-1191 E-ISSN 2540-9204 (C) 2021 Author(s).

Published by LP2M INSURI Ponorogo, this is an open access journal article licensed CC-BY-SA.

DOI: 10.37680 /adabiya.v16i2.1072 


\section{Pendahuluan}

Sebagai salah satu penyangga kekayaan khazanah budaya Mataram dengan keberadaan Kasunanan Surakarta dan Pura Mangkunegaran, Surakarta atau Solo masih menjadi lokasi yang diperhitungkan dalam meneruskan dan menjaga warisan leluhur budaya Jawa. Selain itu, kemajemukan kota ini bukan hanya terlihat dari sisi kebudayaan, namun juga dari sisi keagamaan di mana banyaknya organisasi kemasyarakatan (ormas) yang ada dan lahir di sana sehingga semakin menambah keragamannya. Selain Muhammadiyah, NU, dan Persis yang merupakan ormas Nasional, ada juga Dewan Syariah Kota Surakarta, Majelis Tafsir al-Qur'an (MTA) yang tumbuh dan berkembang dari Solo, dan lain sebagainya. Selain itu secara jalur geografis, Solo juga menjadi titik pertemuan 3 kota besar di tengah Jawa, yakni Yogyakarta, Solo, dan Semarang (Joglosemar), sehingga akses transportasi darat selalu melewati kota ini. Hal demikian menunjukkan kompleksitas Kota Solo yang membedakannya dengan kota lainnya.

Secara historis, Solo juga menjadi pusat pergerakan nasional menjelang kemerdekaan, misalnya Sarekat Dagang Islam yang didirikan oleh Samanhudi dan kemudian beralih menjadi Sarekat Islam yang dipimpin oleh HOS Cokroaminoto. Organisasi ini merupakan organisasi yang jelas-jelas menentang kolonialisme Belanda. Transisi iklim politik Indonesia dari era otoritarian ke arah politik demokrasi telah memunculkan konstelasi gerakan yang spesifik di Kota Solo. ${ }^{1}$ Dalam hal ini, Solo seringkali diidentikkan dengan gerakan radikalisme seperti Jama'ah Islamiyah (JI, lahir 1993) yang didirikan oleh Abu Bakar Ba'asyir, Majelis Mujahidin Indonesia (MMI, lahir 1999), atau Jamaah Anshorut Tauhid (JAT, lahir 2008), FPIS, Laskar Jundullah, Laskar Umat Islam Surakarta (LUIS), Hawariyyun, dan lain sebagainya. ${ }^{2}$ Berkaitan dengan lembaga pendidikan tinggi yang ada di sekitar Solo Raya, secara garis besar terdapat tiga perguruan tinggi besar yaitu Universitas Sebelas Maret (UNS), Universitas Muhammadiyah Surakarta (UMS), dan Institut Agama Islam Negeri (IAIN) Surakarta yang saat ini beralih menjadi Universitas (UIN) Raden Mas Said Surakarta. Karena posisinya berada di Solo, masingmasing perguruan tinggi tersebut memiliki pergaulan ideologis yang cukup beragam.

Terkait dengan persoalan ideologi di kampus, saat ini Indonesia sedang menghadapi permasalahan intoleransi dan radikalisme di berbagai sektor salah satunya di bidang pendidikan kalangan pelajar dan mahasiswa. ${ }^{3}$ Semakin kompleksnya tantangan di dunia pendidikan sekaligus ditandai dengan menjamurnya kelompok mahasiswa yang mengeksklusifkan dirinya dan menyusup di Perguruan Tinggi. ${ }^{4}$ Berangkat dari masalah lemahnya pemahaman agama, fanatisme dan eksklusivisme, maka kebijakan Kementerian Agama diarahkan untuk memperkuat moderasi beragama sebagai pondasi cara pandang, sikap dan praktik beragama. Moderasi beragama diharapkan dapat diturunkan ke dalam rencana strategis setiap Kementerian dan lembaga negara sehingga permasalahan intoleransi dan radikalisme dapat diatasi. Apalagi di era sekarang semakin

\footnotetext{
${ }^{1}$ Muzayyin Ahyar, "Membaca Gerakan Islam Radikal Dan Deradikalisasi Gerakan Islam,” Walisongo: Jurnal Penelitian Sosial Keagamaan 23, no. 1 (2015): 1-26, https://doi.org/10.21580/ws.2015.23.1.220.

${ }^{2}$ Ahyar.

${ }^{3}$ Yedi Purwanto et al., "Internalisasi Nilai Moderasi Melalui Pendidikan Agama Islam Di Perguruan Tinggi Umum," EDUKASI: Jurnal Penelitian Pendidikan Agama Dan Keagamaan 17, no. 2 (2019): 110-24, https://doi.org/10.32729/edukasi.v17i2.605.

${ }^{4}$ Tim Penyusun Kementerian Agama, Moderasi Beragama (Jakarta: Badan Litbang dan Diklat Kementerian Agama RI, 2019).
} 
berkembangnya zaman, justru terjadi degradasi moral generasi penerus bangsa seperti banyak terjadi kasus penyebaran berita bohong atau hoaks dan permasalahan lainnya. ${ }^{5}$

Oleh karena itu, dengan memperhatikan Surakarta sebagai melting pot atau tempat bermuaranya pandangan dan aliran keagamaan sehingga berdampak pada perbedaan latar belakang mahasiswa di perguruan tinggi, dalam hal ini adalah UIN Raden Mas Said yang sebagian besar mahasiswanya berasal dari Solo Raya, maka mutlak diperlukan adanya upaya pencegahan terhadap potensi masuknya paham intoleran di tempat tersebut guna mengantisipasi radikalisme.

Penelitian sebelumnya (tahun 2014) menyebutkan bahwa ada sekelompok organisasi kemahasiswaan, yakni Gerakan Tarbiyah dalam P3KMI di Fakultas Ilmu Tarbiyah, yang menjadi media penyebaran paham keagamaan yang berkarakter transnasional. ${ }^{6}$ Hal ini menjadi bukti yang menunjukkan eksistensi salah satu aliran keagamaan di kalangan mahasiswa di UIN Raden Mas Said Surakarta.

Selanjutnya menurut riset lainnya (tahun 2019), terkait dengan gerakan Islam eksklusiftransnasional di Perguruan Tinggi Negeri, merujuk pada penelitian LPPM UNUSIA Jakarta, menjelaskan bahwa terdapat delapan perguruan tinggi negeri yang dikhawatirkan dapat menjadi lahan tumbuhnya radikalisme di kampus, yakni Institut Agama Islam Negeri (IAIN) Purwokerto, Universitas Jenderal Soedirman Purwokerto, Universitas Negeri Semarang (UNNES), Universitas Diponegoro Semarang, Universitas Negeri Yogyakarta, Universitas Gadjah Mada Yogyakarta, UNS Surakarta, dan IAIN Surakarta. Hal Itu didasarkan pada eksistensi gerakan Islam di perguruan tinggi tersebut yang berafiliasi terhadap 3 gerakan yaitu: Salafi, Gema Pembebasan (HTI), dan KAMMI. Adapun di IAIN Surakarta sendiri didapatkan hasil yang cenderung steril dari gerakan bawah Islam Eksklusif, kegiatan dakwah tersebut hanya sebatas pada Lembaga Dakwah Kampus (LDK) yang dilakukan di masjid. Meskipun demikian, banyaknya kelompok gerakan Islam transnasional di sekitar IAIN Surakarta berdampak pada tingkat potensi intoleransi yang berkembang di kampus. ${ }^{7}$

Dengan memperhatikan beberapa fenomena di atas, penulis ingin mengungkap tentang ketahanan atau daya tahan mahasiswa kampus UIN Surakarta dalam menjaga dan mempertahan sikap moderat, inklusif, dan toleran di tengah banyaknya afiliasi keagamaan di Solo. Daya tahan yang dimaksud artinya mahasiswa memiliki kekuatan mampu menghindari infiltrasi pemahaman yang berpotensi menyebabkan sikap yang intoleran dan radikal akibat arus pergaulan keagamaan yang begitu beragam. Penelitian ini membahas tentang tingkat inklusifitas mahasiswa UIN Raden Mas Said dalam menyikapi segala perbedaan aliran dan tradisi keagamaan. Posisi UIN Raden Mas Said Surakarta yang dikelilingi ragam pergaulan ideologi diasumsikan berdampak terhadap latar belakang dan corak pemikiran mahasiswanya yang dikhawatirkan berpotensi ke arah intoleransi yang berujung menjadi media penyebaran paham yang radikal. Penelitian ini diharapkan bisa menjawab penelitian-penelitian sebelumnya terkait kampus-kampus yang berpotensi menjadi lahan penyebaran paham yang ekstrem bercorak transnasional. Hal ini

\footnotetext{
5 Demsy Jura, "Religious Moderation: An Approach of Religious Life in Indonesia," Jurnal Inovasi Penelitian 1, no. 10 (2021), https://doi.org/10.47492/jip.v1i10.407.

${ }^{6}$ Toto Suharto and Ja'far Assagaf, "Membendung Arus Paham Keagamaan Radikal Di Kalangan Mahasiswa PTKIN," Al-Tahrir: Jurnal Pemikiran Islam 14, no. 1 (2014): 157, https://doi.org/10.21154/al-tahrir.v14i1.72.

${ }^{7}$ LPPM UNUSIA, "Islam Eksklusif Transnasional Merebak Di Kampus-Kampus Negeri” (Jakarta, 2019).
} 
sekaligus menggambarkan situasi terkini tingkat inklusifitas mahasiswa UIN Raden Mas Said yang juga berada di tengah arus pemberitaan gerakan-gerakan eksklusif di sekitar Solo Raya.

\section{Metode}

Dalam penelitian ini digunakan pendekatan kualitatif dengan mengumpulkan penelitian terdahulu yang relevan baik berupa artikel, buku, media massa, maupun berita online. Selain itu untuk memperkuat data kualitatif, penulis juga melakukan observasi ke lokasi atau objek kajian yang hendak dibahas dengan melakukan penggalian informasi melalui penyebaran formulir survei dengan responden mahasiswa UIN Raden Mas Said.

Banyaknya aliran keagamaan di Solo juga akan dilihat aspek kesejarahan (historical approach) dari peta pergerakan pada masa lalu kemudian bergerak ke masa sekarang. Kemudian, akan dianalisis tentang pengaruh eksistensi kemajemukan aliran atau ormas keagamaan terhadap latar belakang ideologis mahasiswa di kampus PTKIN seperti UIN Raden Mas Said Surakarta ini.

Lebih lanjut, untuk menganalisis daya tahan perguruan tinggi di tengah arus aliran dan ormas keagamaan, akan digunakan pendekatan teori fungsionalisme struktural Talcott Parsons dengan model AGIL (adaptation, goal attainment, integration, dan latency). Sosiolog Amerika Talcott Parsons bersama dengan murid-muridnya pada 1950-an menggagas teori fungsionalisme struktural ini dengan alasan bahwa teori tersebut dapat diterapkan untuk memahami sistem apa pun. Berawal dari pola sosiologis Max Weber, Parsons mengembangkan fungsionalisme struktural berdasarkan kerangka kerja dan keyakinannya. Norma dan nilai bersama dalam sistem adalah kunci untuk kelangsungan hidup yang sistemik. Parsons memberikan empat syarat agar sistem sosial mencapai stabilitas sistem yaitu: adaptasi, pencapaian tujuan, integrasi dan pemeliharaan pola laten, atau disebut sebagai AGIL. ${ }^{8}$

\section{Pembahasan}

\section{UIN Raden Mas Said sebagai Melting Pot Aliran dan Gerakan Keagamaan di Solo Raya}

Sebagaimana disebutkan dalam latar belakang, bahwa kampus UIN Raden Mas Said Surakarta (selanjutnya ditulis UIN Surakarta atau UIN Solo) berada di tengah kepungan ragam corak ideologi. Hal ini memungkinkan terjadinya konflik pemahaman mahasiswa yang ada di dalamnya. Oleh karena itu, diperlukan operasi pencegahan dan deteksi dini dari pihak kampus untuk meminimalisasi adanya pergerakan mahasiswa yang mengarah terhadap eksklusivisme dan berujung pada sikap radikal.

Posisi arus pertemuan sikap keagamaan mahasiswa dapat dianalisis melalui Teori Melting Pot yang dicanangkan oleh J. Hector dari Normandia. Bermula saat imigran datang ke Amerika Serikat dan bercampur serta berbaur dengan budaya tempatan untuk menciptakan satu budaya

8 Talcott Parsons, The Structure of Social Action (New York N.Y.: McGraw-Hill Book Company, 1937); Akhmad Rizqi Turama, "Formulasi Teori Fungsionalisme Struktural Talcott Parsons," EUFONI: Journal of Language, Literary and Cultural Studies 2, no. 2 (2018): 58-69, https://doi.org/10.32493/efn.v2i2.5178; Mohammad Syawaludin, "Alasan Talcott Parsons Tentang Pentingnya Pendidikan Kultur," Ijtimaiyya 7, no. 1 (2014): 919-28, https://doi.org/10.24042/ijpmi.v7i2.929. 
baru. Imigran Amerika Serikat yang berasal dari berbagai belahan dunia lain seperti Cina, Irlandia, Meksiko, Rusia, dan sebagainya, ketika mereka semua menjadi penduduk Amerika Serikat, maka yang terjadi adalah budaya mereka berbaur bersama. ${ }^{9}$ Analogi melting pot ini dapat pula dikaitkan dengan banyaknya ragam ormas dan afiliasi gerakan keagamaan yang bertemu di satu wilayah eks-Karesidenan Solo Raya dan tentunya membentuk iklim dan praktik keberislaman yang berbeda.

Dari aspek peta keberagaman praktik ibadah di daerah Solo, melalui pengalaman penulis, tidak cukup sulit di sekitar Kartasura menemukan masjid atau mushala yang dalam praktik ibadahnya terdapat perbedaan. Sebagai contoh adalah, ada satu masjid atau mushala yang praktik salat Shubuh-nya menggunakan do'a Qunut, sedangkan mushala lainnya tidak menggunakan, meskipun beberapa masjid dan mushala itu masih dalam lokasi yang cukup berdekatan di dalam satu RT atau Kelurahan. Dalam penelusuran di Pasar Kliwon, misalnya, terdapat Majlis Ta'lim Ar-Raudhah pimpinan Habib Novel al-Idrus; namun tak jauh dari basis dakwah kelompok Alawiyyin tersebut juga terdapat kantor Majelis Tafsir al-Qur'an (MTA) yang secara tipologi dakwah jauh berbeda. Contoh lain, tradisi Grebeg Muludan Sekaten yang terpusat di alun-alun Kasunanan Surakarta juga tak jauh dari sentral tradisi Haul Habib Ali al-Habsyi.

Dalam konteks Surakarta yang menjadi bagian dari Karesidenan Solo Raya, Kawasan ini juga menjadi lahan tumbuhnya gerakan islamisme radikal yang mempunyai karakteristik anti kemaksiatan, anti terhadap pemerintahan demokratis, dan menuntut bahkan memperjuangkan penerapan syariat Islam. Lebih lanjut, menurut Muzayyin Ahyar, kemunculan kelompok tersebut secara kronologis mempunyai akar historis dengan gerakan Islamisme pra-Kemerdekaan, yakni Sarekat Dagang Islam (SDI) yang beralih menjadi Sarekat Islam (SI). Selain itu, terdapat juga sosok Haji Misbah dengan ide Sosialisme-Komunismenya yang seolah membingkai dua ide itu dalam satu gerakan sosial. Kemudian, pada masa pra-Reformasi, gerakan Islamisme di Solo dimotori oleh keturunan Arab Hadhramaut, Abdullah Sungkar, yang melanjutkan gerakan Darul Islam Kartosuwiryo. Pada perkembangannya, gerakan Abdullah Sungkar itu disambut baik oleh Abu Bakar Ba'asyir, seorang mubaligh pendiri Pesantren Ngruki. Keduanya mengajar 12 kader ulama, di antaranya Abdullah Thufail yang mendirikan Majelis Tafsir al-Qur'an (MTA) dan Abdullah Marzuki yang mendirikan pesantren as-Salam Solo. ${ }^{10}$ Dengan demikian, dewasa ini Surakarta menjadi titik temu (melting pot) aliran-aliran keislaman yang bercorak moderat seperti representasi Nahdlatul Ulama dan Muhammadiyah serta kelompok fundamentalis yang diwakili oleh salah satu kelompok-kelompok lokal tersebut di atas.

Dari kalangan pesantren, di Solo terdapat beberapa pesantren yang memiliki tipologi berbeda-beda, seperti al-Muayyad Mangkuyudan, al-Mukmin Ngruki, dan As-Salam. Masingmasing pesantren ini memiliki model kurikulum dan karakteristik pola pemahaman agama yang berbeda. Ditambah lagi fenomena Syekher Mania (kelompok penggemar mubaligh Habib Syekh) yang juga berpusat di Solo seolah menjadi pelengkap bahwa selain banyaknya eksistensi aliran di kota ini sangat kompleks. Ada yang anti tradisi sebagaimana kelompok-kelompok radikal, ada juga kelompok yang masih memegang teguh budaya lokal seperti Muludan (peringatan maulid Nabi) dan sebagainya.

9 Dede Rosyada, "Pendidikan Multikultural Di Indonesia Sebuah Pandangan Konsepsional," SOSIO DIDAKTIKA: Social Science Education Journal 1, no. 1 (2014), https://doi.org/10.15408/sd.v1i1.1200.

${ }^{10}$ Ahyar, "Membaca Gerakan Islam Radikal Dan Deradikalisasi Gerakan Islam." 
Terkait dengan dinamika gerakan keagamaan di perguruan tinggi di Solo, khususnya di PTKIN, pada tahun 2017 di IAIN Surakarta terjadi aksi demonstrasi dari beberapa anggota atau simpatisan ormas Dewan Syariah Kota Surakarta untuk menolak kegiatan bedah buku salah satu tokoh Syiah di Indonesia, Haidar Bagir. Kelompok demonstran tersebut menolak kedatangannya dengan alasan bahwa kampus keagamaan IAIN Surakarta tidak boleh terinfiltrasi paham Syiah yang mereka anggap sesat. ${ }^{11}$ Meskipun penolakan terjadi, namun acara bedah buku tersebut tetap berlanjut, karena pihak rektorat berpendapat bahwa budaya akademis di perguruan tinggi harus tetap dipertahankan selama tidak melanggar kaidah hukum dan norma yang berlaku.

Contoh lain adalah yang terjadi tahun 2020, yakni aksi anarkisme-intoleransi berbau sentimen agama. Di Kelurahan Mojo, Kecamatan Pasar Kliwon, beberapa anak melakukan pengrusakan makam karena makam tersebut merupakan makam orang Kristen. Kasus intoleransi tersebut bahkan menjadi isu Nasional karena dilakukan oleh anak-anak kecil yang berumur di bawah 12 tahun. Terlebih, kejadian itu dilakukan saat merebaknya kasus Covid-19 yang melarang adanya pertemuan tatap muka di sebuah rumah belajar. ${ }^{12}$ Selain itu, ketika ramai kontroversi ceramah salah satu tokoh NU dari Yogyakarta, Gus Muwafiq, terkait masa kecil Nabi Muhammad, di Surakarta terjadi demonstrasi besar yang cenderung anarkis di depan kantor Cabang NU setempat. Unjuk rasa yang dilakukan oleh massa dari Dewan Syariah Kota Surakarta (DSKS) ini memicu anarkisme karena berhadapan dengan beberapa aktivis NU, terutama Banser dan Pagar Nusa. ${ }^{13}$ Dari sudut pandang pemberitaan Nasional, Solo juga tidak luput dari hal-hal yang berkaitan dengan isu-isu radikal, kelompok teror, dan isu garis keras lainnya. Berita tentang beberapa teroris yang ditangkap Detasemen Khusus 88 Antiteror Polri di Solo makin mengesankan bahwa kota Solo adalah sarang teroris. ${ }^{14}$

Berbicara mengenai aksi terorisme, terdapat beberapa jaringan teroris yang tertangkap di Solo, seperti Noordin M Top yang juga terdeteksi dan meninggal tertembak di Solo. Tepatnya 17 September 2009, Noordin M Top disergap oleh Densus 88 di salah satu rumah di Kampung Kepoh Sari, Mojosongo, Jebres, Solo. Penyergapan itu berujung baku tembak yang kemudian menewaskan empat orang, termasuk dalang di balik serangan Bom Bali I Noordin M Top. ${ }^{15}$

Bahkan, terdapat pula fakta sejarah bahwa ada mahasiswa UIN Raden Mas Said (saat itu masih STAIN Surakarta) yang pada tahun 2006 terlibat meninggal bersama Dr. Azahari, salah satu pelaku aksi terror, dalam sebuah penyergapan oleh Densus 88 di Kota Batu Malang. Meskipun mahasiswa dari Jurusan Syariah tersebut sudah tidak melanjutkan kuliah sejak semester 3, tapi hal itu menunjukkan bahwa kampus di Solo ini dikelilingi pergaulan yang perlu diwaspadai. ${ }^{16}$

Pada tahun 2019 terjadi peristiwa pemboman Pos Polisi Kartasura oleh seorang pemuda berusia 22 tahun. Model aksi yang dilancarkan adalah bom bunuh diri seperti di tempat-tempat

\footnotetext{
${ }^{11}$ Yudha Satriawan, "Bedah Buku Di Kampus IAIN Surakarta Didemo Ratusan Anggota Ormas Islam,” VOA Indonesia, 2017.

12 Tito Dirhantoro, “Ini Motif 7 Anak Yang Merusak Makam Di Solo, Kini Jadi Tersangka,” Kompas.tv, 2021.

13 Ichsan Kholif Rahman, "Bentrok Usai Demo Protes Gus Muwafiq, PCNU Solo: Malu! Mau Sampai Kapan?," Solopos, 2019.

${ }^{14}$ Fajar Abrori, “Densus 88 Tangkap 6 Teroris Di Solo Terkait JAD Kendal,” Liputan6, 2020.

15 Rosy Dewi Arianti Saptoyo, "Hari Ini Dalam Sejarah: Teroris Noordin M Top Tewas Di Solo," Kompas.com, 2021.

${ }^{16}$ Moh Ashif Fuadi et al., "Strengthening Religious Moderation to Counter Radicalism at IAIN Surakarta," Al-Tahrir: Jurnal Pemikiran Islam 21, no. 02 (2021): 261-84, https://doi.org/10.21154/altahrir.v21i2.3102.
} 
lain. Setelah dilakukan penyelidikan, pemuda tersebut rupanya seorang lulusan SMA yang bekerja sebagai penjual gorengan (makanan ringan) dan berafiliasi dengan aliran ISIS. Polisi menyatakan bahwa pelaku yang bernama Rofik ini masih amatir, karena aparat belum menemukan rekam jejak aksinya di tempat lain. ${ }^{17}$

Dari berbagai gambaran di atas, dapat diambil kesimpulan bahwa Kota Solo memiliki keunikan dalam sisi pergerakan keagamaan. Begitu derasnya perkembangan arus pemahaman keagamaan di wilayah tersebut membentuk pola gerakan yang variatif, bahkan beberapa di antaranya cenderung radikal dan intoleran. UIN Raden Mas Said Surakarta sebagai kampus keagamaan tentu saja harus mempersiapkan strategi melalui sebuah kebijakan untuk mengantisipasi gerakan terselubung yang dapat mengganggu stabilitas perguruan tinggi, sehingga asumsi masuknya kelompok intoleran dan radikal mampu dicegah dengan baik.

\section{Penguatan Moderasi Keberagamaan Mahasiswa: Upaya Inklusifisasi dan Pencegahan Intoleransi}

Di IAIN Surakarta (pra-UIN), terdapat unit Program Pendampingan Pengembangan Kepribadian Muslim Integral (P3KMI) yang mulanya hanya berfokus pada kegiatan belajar membaca dan menulis al-Qur'an (BTQ) untuk menyesuaikan kebutuhan mahasiswa yang sebagian berasal dari sekolah berlatarbelakang lembaga formal umum non-keagamaan sehingga belum menguasai baca tulis al-Qur'an. Namun, bersamaan dengan berkembangnya arus gerakan tarbiyah di UIN Raden Mas Said, ternyata P3KMI juga menjadi media penyaluran paham puritan. Melalui program liqa' (kajian keagamaan berkala), para aktivis gerakan ini menyelipkan pemahaman mereka melalui buku panduan dan proses indoktrinasi melalui pembelajaran baca tulis al-Qur'an (BTQ) dan praktik ibadah. ${ }^{18}$ Oleh karena itu, diperlukan suatu program yang dapat mengimbangi hal tersebut serta dapat menjadi upaya pembentukan aspek moderasi beragama mahasiswa. Bermula dari Fakultas Adab dan Bahasa yang membentuk Bilik Moderasi Islam dan Adab (BIMA), pada tahun 2019 P3KMI beralih nama menjadi BIMA yang mana di dalamnya berisi materi tentang moderasi beragama dan pengembangan adab dan akhlak. Adapun materi baca tulis al-Qur'an dialihkan menjadi tugas dari program Unit Pondok BTQ Fakultas Adab dan Bahasa. Hal itu mengacu keputusan rektor Institut Agama Islam Negeri Surakarta Nomor 392 Tahun 2019.

Jika dianalisis dengan teori strukturalisme fungsional Talcott Parsons yang mengemukakan bahwa agar sistem organisasi sosial dapat bertahan, maka sistem harus memiliki empat hal yang disebut dengan AGIL, maka langkah-langkah yang dilakukan oleh UIN Surakarta adalah sebagai berikut:

Pertama, adaptation (adaptasi), yaitu sistem harus menyesuaikan diri dengan lingkungan dan menyesuaikan lingkungan dengan kebutuhan. ${ }^{19}$ Ma'unah menjelaskan bahwa adaptasi yang dimaksud Parsons adalah keadaan di mana suatu sistem sudah menemukan cara untuk mengatasi permasalahan yang terjadi sangat wajar jika sistem ini mengalami perubahan-perubahan agar

\footnotetext{
${ }^{17}$ Audrey Santoso, "Polisi: Pelaku Bom Kartasura Sukoharjo Terpapar Paham ISIS,” Detik.com, 2019.

${ }^{18}$ Suharto and Assagaf, "Membendung Arus Paham Keagamaan Radikal Di Kalangan Mahasiswa PTKIN."

19 Samsul Bahri, "Perspektif Teori Struktural Fungsionalisme Tentang Ketahanan Sistem Pendidikan Pesantren," MIQOT: Jurnal Ilmu-Ilmu Keislaman 40, no. $1 \quad$ (2016): 88-105, https://doi.org/10.30821/miqot.v40i1.221.
} 
masalah segera terselesaikan. ${ }^{20}$ Sistem adaptasi yang dilakukan di lembaga kampus sangat jelas apabila melihat fungsi perguruan tinggi yang memposisikan sebagai Tri Dharma Perguruan Tinggi yang meliputi pendidikan, penelitian, dan pengabdian. Adaptasi ini dilakukan oleh institusi-institusi terkait untuk mencapai perubahan. Pada kasus intoleransi yang berujung radikalisme di kampus, sistem adaptasi disesuaikan oleh UIN Surakarta dalam program Tri Dharma Perguruan Tinggi sehingga deteksi dini dalam upaya pencegahan benih radikalisme bisa diatasi.

Kedua, goal attainment (pencapaian tujuan), yaitu sebuah sistem harus mendefinisikan dan mencapai tujuan utamanya. ${ }^{21}$ Tujuan yang telah ditetapkan harus menyangkut kepentingan masyarakat dan bukan kepentingan personal maupun kelompok. Pada sistem ini tujuan pendidikan di kampus adalah mendidik mahasiswa sebagai agent of change (agen perubahan) agar menjadi lulusan yang ahli di bidangnya masing-masing sehingga mampu mewujudkan tercapainya pendidikan nasional.

Ketiga, integration (integrasi), pada hakikatnya memperhatikan dan mengatur hubungan antara bagian-bagian yang menjadi komponennya. ${ }^{22}$ Berkaitan dengan integrasi dalam konteks perguruan tinggi dapat dilihat dari upaya UIN Surakarta dalam mengatur lembaga-lembaganya agar tidak disusupi kelompok garis keras yang menyasar mahasiswa untuk menjadi anggotanya.

Keempat, latency (pemeliharaan pola-pola), bahwa sebuah sistem harus dapat memelihara, melengkapi dan memperbaiki baik motivasi individual maupun pola-pola kultural. ${ }^{23}$ Pada prasyarat terakhir ini, untuk memelihara pola-pola yang telah ada di kampus para pemangku kebijakan di UIN Surakarta mengambil langkah yang sama yaitu selalu memberikan pembinaan atau edukasi kepada mahasiswa tentang Islam moderat sehingga tidak gampang terpancing pada isu-isu yang berbau agama dan tidak mudah untuk terprovokasi serta melakukan tindakan anarkis. Dijelaskan sebelumnya bahwa lokasi kampus di tengah banyaknya aliran gerakan keagamaan di Solo sangat dimungkinkan pergaulan itu juga berdampak di kampus, sehingga diperlukan langkah deteksi dini dalam rangka pencegahan upaya infiltrasi (penyusupan) gerakan mahasiswa yang cenderung intoleran dan mengarah kepada radikalisme.

Untuk merespons adanya infiltrasi gerakan keagamaan yang terlarang di kampus, Rektor UIN Surakarta menyatakan beberapa implementasi moderasi beragama di kampus tersebut, yang pertama, adalah dibentuknya unit Rumah Moderasi Beragama lengkap dengan pengurus beserta program-programnya. Kemudian, yang kedua, dibentuk Pusat Studi Pancasila dan Kebangsaan (PSPK) yang bertujuan untuk menyegarkan kembali nilai-nilai Pancasila dalam kehidupan di kampus. Yang ketiga, walaupun tidak berkaitan langsung dengan isu ini, adalah dibentuknya unit Pusat Kajian dan Pengembangan Pesantren Nusantara (PKPPN) yang bertujuan memberdayakan dan pembangunan pesantren selalu mengkampanyekan Islam yang santun di setiap kesempatan. Lembaga terakhir ini, seiring dengan peralihan IAIN ke UIN, bertransformasi menjadi Pusat Pengkajian Masyarakat dan Pendidikan Islam Nusantara (PPM-PIN). Selain itu, juga

${ }^{20}$ Binti Maunah, "Pendidikan Dalam Perspektif Struktural Konflik," CENDEKIA: Journal of Education and Teaching 9, no. 1 (2016): 71, https://doi.org/10.30957/cendekia.v9i1.53.

${ }^{21}$ Bahri, "Perspektif Teori Struktural Fungsionalisme Tentang Ketahanan Sistem Pendidikan Pesantren."

${ }^{22}$ Maunah, "Pendidikan Dalam Perspektif Struktural Konflik."

${ }^{23}$ Wiliansyah Pikoli, Yosafat Hermawan Trinugraha, and Yuhastina Yuhastina, "Peran Tokoh Agama Islam, Hindu, Dan Kristen Dalam Menjaga Kerukunan Beragama Di Desa Banuroja, Gorontalo," Al-Adabiya: Jurnal Kebudayaan Dan Keagamaan 16, no. 1 (2021): 94, https://doi.org/10.37680/adabiya.v16i1.827. 
dikembangkan penelitian-penelitian bertemakan moderasi beragama yang dikelola oleh unit Lembaga Penelitian dan Pengabdian Masyarakat (LP2M).

\section{Kampanye Moderasi Beragama di UIN Raden Mas Said Surakarta}

Istilah moderasi beragama di Indonesia seringkali diidentikan dengan konsep wasathiyah yang disampaikan dalam potongan ayat al-Qur'an "wa kadzālika ja'alnākum ummatan wasathan" (telah kami jadikan kalian ummatan wasathan - umat yang adil, yang tengah-tengah). ${ }^{24}$ Urgensi posisi di tengah-tengah adalah karena dalam kajian ilmu Kalam terdapat yang dinamakan dengan tatharruf tasyaddud (ekstrem kanan) dan tatharruf tasahhul (ekstrem kiri). ${ }^{25}$

Ekstrem kanan ditandai dengan ideologi puritanisme agama. Puritanisme diambil dari akar kata pure (murni). Kelompok yang puritan ingin mengembalikan ajaran agama kepada ajaran yang murni, sebagaimana jargon “mari kembali kepada al-Qur'an dan Hadis”. Puritanisme agama berimplikasi pada penghapusan segala kegiatan keagamaan yang bersatu dengan tradisi dan berkolaborasi dengan kebudayaan, seperti peringatan Maulid Nabi, tahlilan, ziarah kubur, peringatan haul, dan lain-lain, karena dianggap bid'ah dan sesat. ${ }^{26}$

Tanda berikutnya dari ekstrem kanan adalah fenomena fundamentalisme dan radikalisme. Hal ini merupakan dua hal yang berkelindan, saling berhubungan satu dengan yang lain. Fundamentalisme diambil dari akar kata fundamen (dasar), ${ }^{27}$ sedangkan radikalisme diambil dari bahasa latin radix (akar). ${ }^{28}$ Jenis ini memiliki persamaan tetapi satu tingkat di atas puritanisme. Karakteristik utamanya adalah takfiri (kebiasaan mengkafir-kafirkan). Sistem demokrasi, nasionalisme, serta ideologi Pancasila dianggap sebagai wujud kafir dan thaghut. ${ }^{29}$ Sedangkan level atau tanda ketiga dalam kelompok ekstrem kanan adalah yang paling ekstrem, yakni irhabi atau terorisme. Habitat ketiga dari ekstrem kanan ini biasa mengambil ayat al-Qur'an "wa man lam yahkum bimā anzalallahu fa ulāika humul kāfirun" (mereka yang tidak berhukum sesuai dengan hukum Allah maka mereka kafir - halal darahnya, boleh dibom atau boleh dibunuh). ${ }^{30}$

Adapun ekstrem kiri diistilahkan tasahhuli atau biasa disebut liberalisme, diambil dari akar kata to liberate (membebaskan). Berbeda dengan arti Islam yakni tunduk atau pasrah, sikap tasahhul ini berkonotasi terlalu menggampang-gampangkan agama. Meski sebetulnya agama itu mudah, akan tetapi tidak boleh digampang-gampangkan sesuai selera akal. ${ }^{31}$ Dengan demikian, posisi gerakan moderasi beragama jika mengacu pada kelompok kanan dan kiri yakni berada di tengah-tengah dengan tetap berpegang teguh kepada kebenaran. Perwujudannya adalah melalui

${ }^{24}$ Afrizal Nur and Mukhlis Lubis, "Konsep Wasathiyah Dalam Al-Quran; (Studi Komparatif Antara Tafsir Al-Tahrîr Wa at-Tanwîr Dan Aisar at-Tafâsîr)," An-Nur 4, no. 2 (2015): 205-25, http://ejournal.uinsuska.ac.id/index.php/Annur/article/view/2062/1401.

${ }^{25}$ Fuadi et al., "Strengthening Religious Moderation to Counter Radicalism at IAIN Surakarta."

${ }^{26}$ Fuadi et al.

${ }^{27}$ Poerwadarminta, Kamus Besar Bahasa Indonesia (Jakarta: Balai Pustaka, 1990).

${ }^{28}$ Muhammad Harfin Zuhdi, "Radikalisme Agama Dan Upaya Deradikalisasi Pemahaman Keagamaan," AKADEMIKA 22, no. 1 (2017): 92-105, https://e-journal.metrouniv.ac.id/index.php/akademika/article/view/568.

${ }^{29}$ M. Hafidh Widodo, "Ideologi Takfiri Muhammad Al-Maqdisi : Memahami Hubungan Beragama Dan Bernegara Perspektif Maqāshid Asy-Syarī‘Ah,” Living Islam 1, no. 2 (2018), https://doi.org/10.14421/lijid.v1i2.1709.

30 Ahmad Jazuli, "Strategi Pencegahan Radikalisme Dalam Rangka Pemberantasan Tindak Pidana Terorisme," Jurnal Ilmiah KEBIJAKAN HUKUM 2 2, no. $10 \quad$ (2016), https://doi.org/10.30641/kebijakan.2016.V10.197-209.

${ }^{31}$ Fuadi et al., "Strengthening Religious Moderation to Counter Radicalism at IAIN Surakarta." 
sikap yang pertama, tasāmuh (penuh toleransi), yang kedua, tawassuth dan i'tidal (berpegang kepada keadilan), kemudian yang ketiga adalah tawāzun (seimbang). ${ }^{32}$

Quraish Shihab menyebut moderasi atau wasathiyah bukan sikap yang bersifat tidak jelas atau tidak tegas seperti sifat netral dan pasif. Salah satu indikator wasathiyah adalah lemah lembut dan sopan santun, namun bukan berarti tidak boleh menghadapi suatu persoalan dengan tegas. Ciri wasathiyah adalah berlaku adil, yakni menempatkan segala sesuatu pada tempatnya. Salah satu mufasir par excellence Indonesia ini menegaskan bahwa persoalan wasathiyah bukan hanya persoalan orang per orang, melahirkan persoalan umat dan bangsa, apalagi ketika dihadapkan dengan eksistensi aneka macam ideologi yang berkembang. ${ }^{33}$

Dalam konteks keindonesiaan, Azyumardi Azra menyatakan bahwa keberagaman di Indonesia sebetulnya berbeda dengan yang ada di tempat-tempat lain, karena di Indonesia sangat menonjolkan hal-hal yang bersifat inklusif. Terlihat, misalnya, di dalam berbagai bidang keberadaan pemimpin atau pejabat publik dari kalangan non Muslim itu sudah menunjukkan sikap moderasi tinggi dari umat mayoritas Islam yang mencapai 88,2\% dari 260 juta penduduk Indonesia. ${ }^{34}$ Untuk memelihara atau melanjutkan tren positif dalam hal sikap keberagamaan inklusif ini, para pemangku kebijakan, baik dari unsur pemerintah ataupun kelompok Islam moderat, diharapkan untuk mampu melakukan penegakan regulasi dan keberanian dalam melakukan kontranarasi dakwah radikal yang belakangan marak di ranah digital. ${ }^{35}$

Dalam implementasi di UIN Surakarta, perlu dikembangkan literasi yang baik dalam memanfaatkan aneka piranti teknologi digital. Terkait dengan penyebaran isu atau hoaks, UIN Raden Mas Said sudah memasukkan tema moderasi beragama dalam berbagai kegiatan untuk memerangi hoaks, seperti melalui kegiatan Pengenalan Budaya Akademik dan Kemahasiswaan (PBAK), Kuliah Kerja Nyata $(\mathrm{KKN})$, ataupun tema-tema wisuda, tema riset dan kegiatankegiatan lain. Seperti contohnya adalah pada tahun 2020, melalui KKN Kerja Sosial Daring Dari Rumah (Kerso Darma), UIN Surakarta mulai mengusung tema moderasi beragama, dan pada tahun 2021 juga kembali mengusung tema "Penguatan Ketahanan Masyarakat Masa Pandemi Covid-19 Berbasis Kearifan Lokal dan Moderasi Beragama”. ${ }^{36}$

Kampanye moderasi beragama melalui perguruan tinggi ini sangat penting, karena lembaga pendidikan, termasuk juga PTKI, adalah salah satu kunci untuk menghentikan, atau setidaknya memperlambat penyebaran ideologi ekstremis radikal. Sesuai dengan karakter moderasi beragama, pendidikan Islam yang berperan sebagai bentuk pendekatan budaya dalam konterradikalisme, sejatinya memuat empat hal, yaitu: komitmen kebangsaan, toleransi, anti-kekerasan dan akomodatif terhadap kebudayaan lokal. ${ }^{37}$

\footnotetext{
${ }^{32}$ Mohamad Fahri and Ahmad Zainuri, “Moderasi Beragama Di Indonesia,” Intizar 25, no. 2 (2019): 95-100, https://doi.org/10.19109/intizar.v25i2.5640.

${ }^{33}$ M. Quraish Shihab, Wasathiyah; Wawasan Islam Tentang Moderasi Beragama (Tangerang: Lentera Hati, 2019).

34 Azyumardi Azra, “4. Distinguishing Indonesian Islam. Some Lessons to Learn,” in Islam in Indonesia: Contrasting Images and Interpretations, ed. Jajat Burhanuddin and Kees van Dijk (Amsterdam: Amsterdam University Press, 2013), 63-74, https://doi.org/10.1515/9789048516254-005/HTML.

35 Agus Setyawan, "Dakwah Yang Menyelamatkan: Memaknai Ulang Hakikat Dan Tujuan Da'wah Islamiyah," Al-Adabiya: Jurnal Kebudayaan Dan Keagamaan 15, no. $02 \quad$ (2020): 189-99, https://doi.org/10.37680/adabiya.v15i02.487.

${ }^{36}$ LP2M IAIN Surakarta, "Pengumuman Pembagian Kelompok Dan Dosen Pembimbing Lapangan (DPL) KKN Kerso Darma 2021,” LP2M, 2021.

${ }^{37}$ Tim Penyusun Kementerian Agama, Moderasi Beragama.
} 


\section{Respons Mahasiswa terhadap Tema Moderasi Beragama}

Bilik Moderasi Islam dan Adab (BIMA), sebagai salah satu unit pelaksana di UIN Surakarta dalam mengembangkan pembelajaran moderasi beragama dan adab, menginisiasi program pengembangan akhlak yang di dalamnya terdapat kurikulum moderasi beragama sebagai upaya pencegahan radikalisme bagi mahasiswa. ${ }^{38}$ Penulis, sebagai representasi dari BIMA, juga menyelenggarakan survei terkait dengan tema moderasi beragama pada 245 orang mahasiswa. Dari 245 responden yang menjawab pertanyaan, ditemukan beberapa hal yang menarik sebagai berikut.
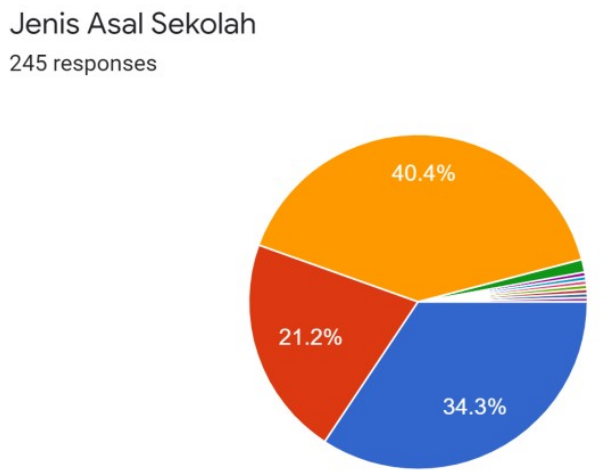

Sekolah Menengah Atas (SMA)

Sekolah Menengah Kejujuran (SMK)...

Madrasah Aliyah (baik Negeri maupun.

UIN Raden Mas Said Surakarta

UIN RADEN MAS SAID SURAKARTA

Madrasah Aliah Swasta

PPIP

Pondok Pesantren Ta'mirul Islam Sura.

$\Delta 1 / 2 \nabla$

Gambar 1. Asal Sekolah Mahasiswa UIN Raden Mas Said Surakarta

Jika melihat diagram pada Gambar 1, ditemukan bahwa peta persebaran asal-usul atau latar belakang pendidikan mahasiswa UIN Surakarta cukup bervariasi. Meskipun didominasi oleh alumni dari Madrasah Aliyah, namun tidak sedikit yang berasal dari SMA dan SMK. Tentu saja hal ini dapat memengaruhi tingkat pemahaman agama yang juga akan menjadi materi pembelajaran di kampus sebagai bagian dari PTKIN.
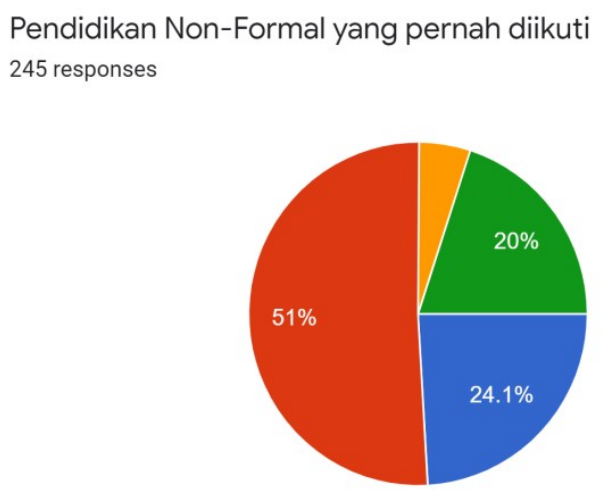

Pondok Pesantren

Taman Pendidikan Al-Qur'an (TPA TPQ)

Madrasah Diniyah

Tidak Pernah

Gambar 2. Pendidikan Non-Formal yang pernah diikuti

Kemudian, pada Gambar 2, berkaitan dengan latar belakang pendidikan non-formal yang pernah diikuti, mayoritas mahasiswa UIN Raden Mas Said Surakarta pernah menempuh Taman

\footnotetext{
${ }^{38}$ Fuadi et al., "Strengthening Religious Moderation to Counter Radicalism at IAIN Surakarta."
} 
Pendidikan al-Qur'an. Hal ini tentunya akan menunjang kemampuan membaca al-Qur'an yang juga menjadi program di PTKIN. Namun, keberadaan persentase yang cukup besar dari kalangan mahasiswa yang belum pernah mengikuti pendidikan keagamaan baik melalui pesantren, TPA, maupun Madrasah Diniyah, menjadi catatan tersendiri bagi UIN Surakarta untuk memformulasikan pembinaan kelompok ini agar terjaga keseimbangan.
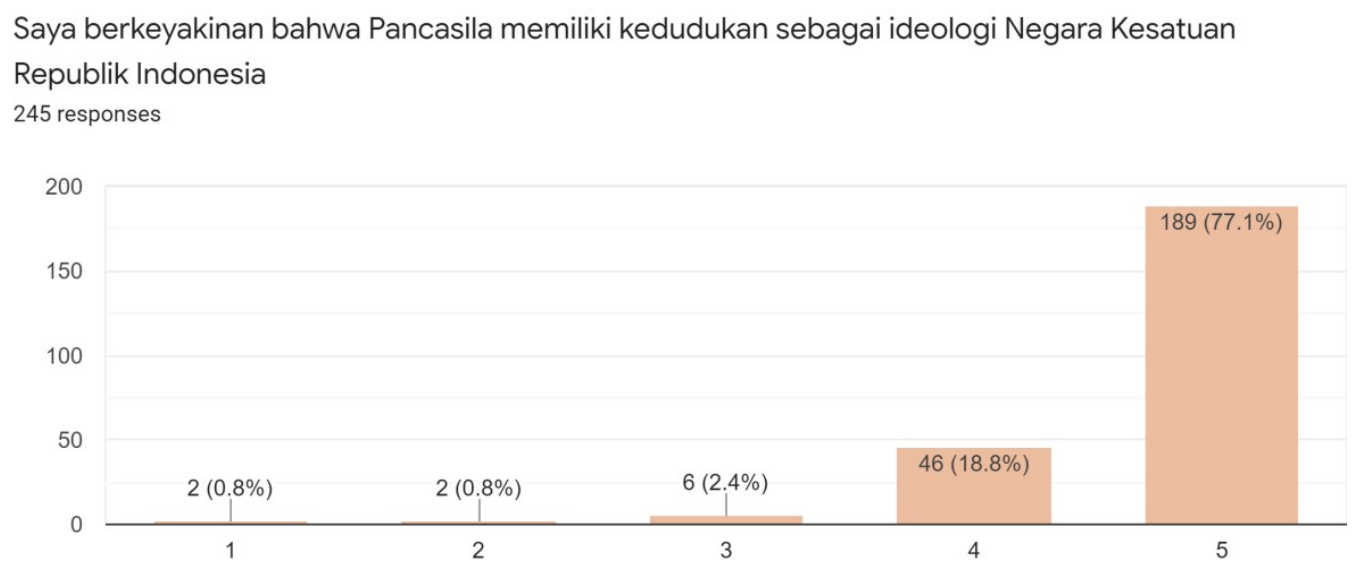

Gambar 3. Keyakinan tentang Pancasila sebagai ideologi NKRI

Berkaitan dengan keyakinan dan penerimaan bahwa Pancasila sebagai ideologi NKRI, mayoritas responden pada Gambar 3 menyatakan bahwa Pancasila masih diyakini dan diakui sebagai ideologi negara. Hanya sedikit saja yang berpendapat lain, sehingga kekhawatiran atas banyaknya aliran keagamaan di Solo Raya berakibat terhadap pola pemikiran mahasiswa dapat dinafikan. Dengan demikian, mahasiswa kampus tersebut masih memiliki sikap moderat terhadap ideologi negara yang cukup tinggi.

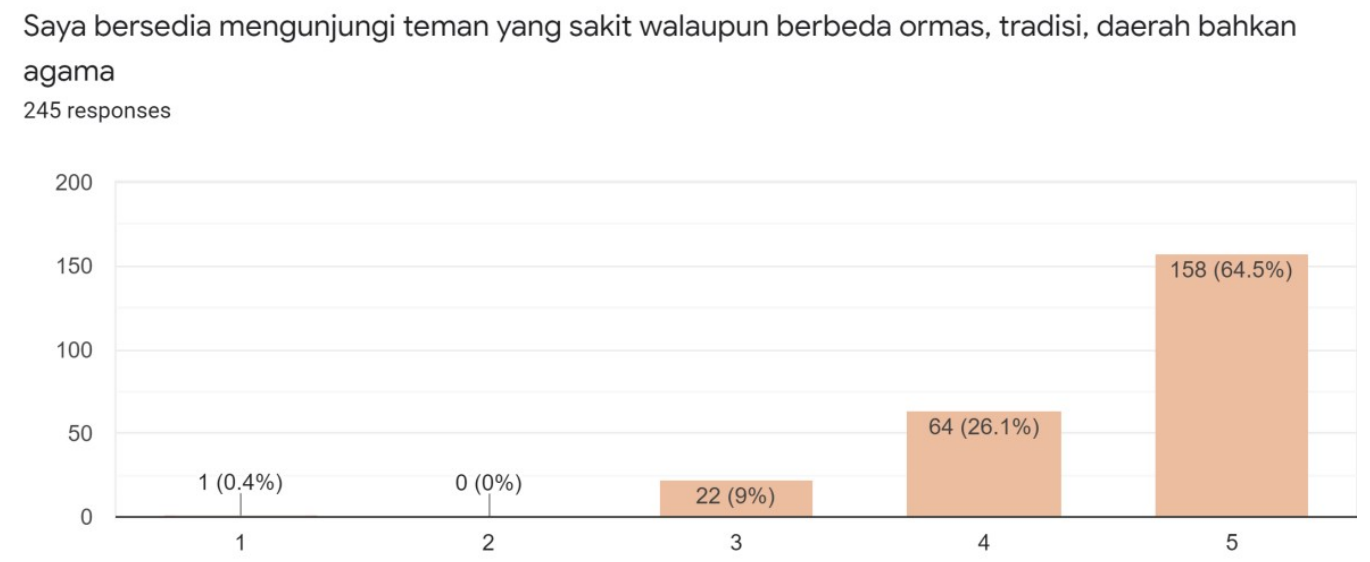

Gambar 4. Toleransi dalam pergaulan sehari-hari

Gambar 4 ini menunjukkan perihal toleransi dalam pergaulan sehari-hari. Berdasarkan pertanyaan survei mengenai keinginan untuk tetap mengunjungi teman yang sakit walaupun berbeda Ormas, tradisi, daerah asal bahkan agama, mayoritas responden masih menunjukkan angka yang cukup toleran, sehingga kekhawatiran di dalam adanya potensi berkembangnya 
kelompok intoleran yang berujung pada radikalisme di kampus masih bisa diantisipasi. Pergaulan ideologi yang cukup beragam di Solo Raya tidak cukup memengaruhi pemikiran mahasiswa menjadi intoleran.

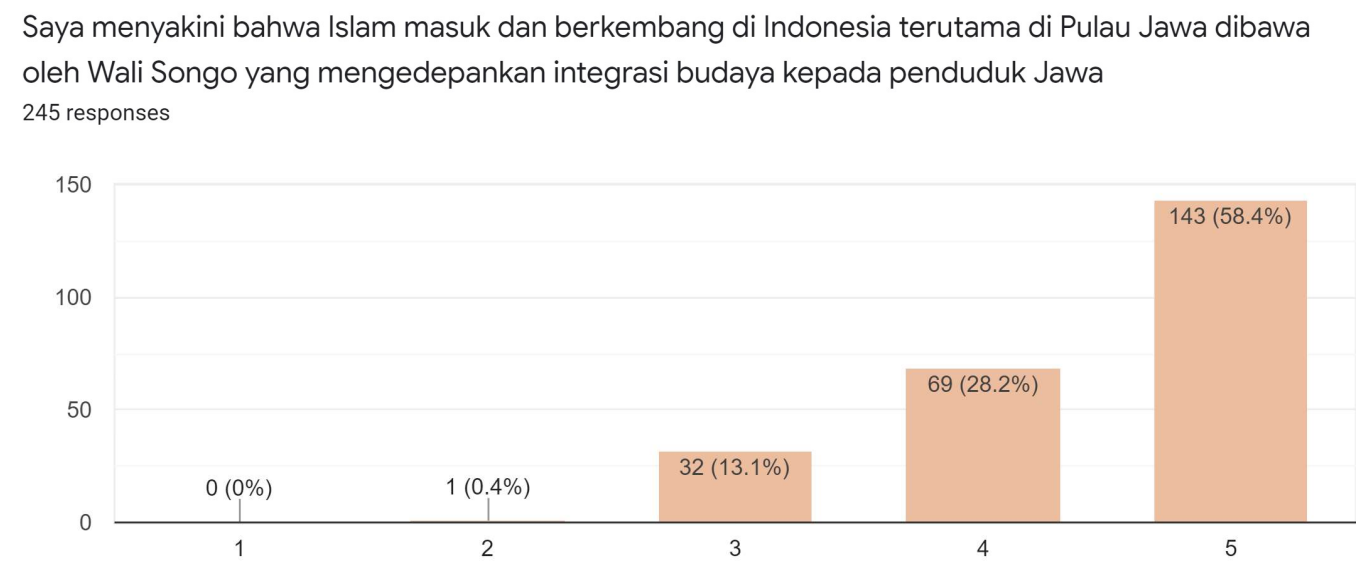

Gambar 5. Sikap terkait integrasi budaya

Berkaitan dengan keyakinan Islam masuk dan berkembang di Indonesia, utamanya di Pulau Jawa, dibawa oleh Walisongo yang mengedepankan integrasi budaya sebagai media dakwah, ada pada Gambar 5. Hasil survei tersebut menunjukkan tingkat persetujuan yang tinggi sehingga mayoritas mahasiswa masih bersedia mengakomodasi budaya lokal sebagai salah satu indikator moderasi beragama. Hal ini sekaligus juga menjadi jawaban bahwa kekhawatiran terhadap kelompok eksklusif yang anti tradisi masih terkondisikan dengan baik.
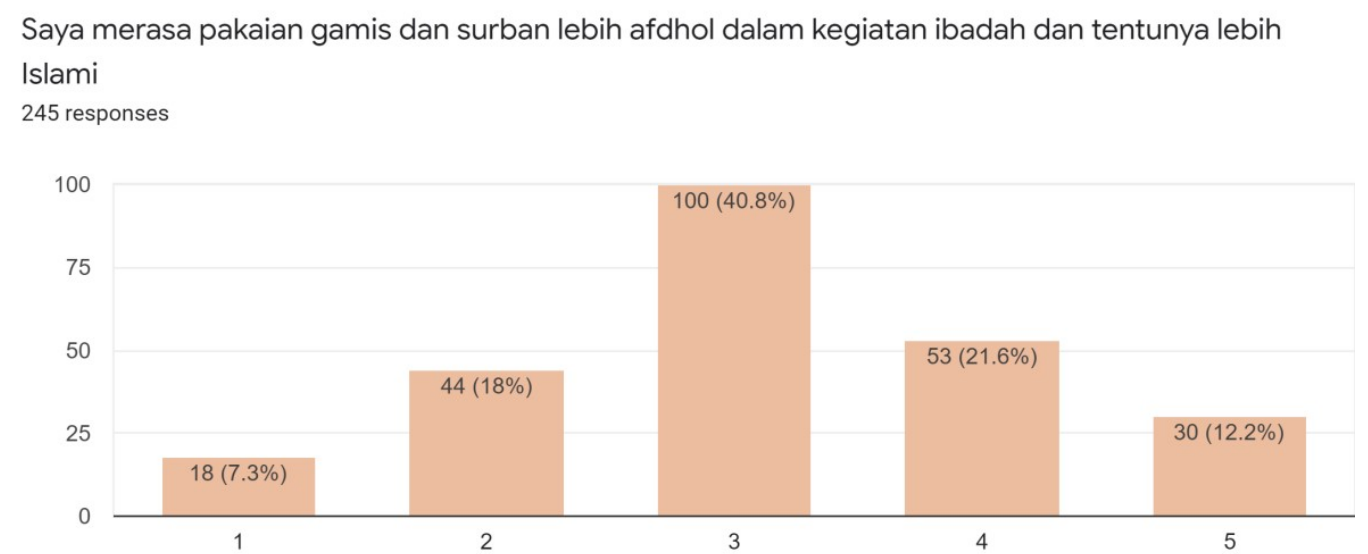

Gambar 6. Sikap terkait pakaian dalam beribadah

Terakhir, dalam Gambar 6, yang cukup menarik adalah tanggapan yang berkaitan dengan ekspresi kebudayaan dengan pernyataan bahwa pakaian gamis dan sorban lebih afdhal (utama) dalam kegiatan Islami. Mayoritas responden memberikan jawaban netral. Artinya, tidak ada keberpihakan antara yang mengekspresikan budaya agama dengan ragam pakaian gamis atau sorban dengan yang tidak memakainya. Terdapat sebuah ekspresi kebebasan dalam sisi pakaian ibadah, sehingga dalam kesehariannya terdapat varian ekspresi tersebut, misalnya menggunakan 
sarung, gamis, sorban dan lain sebagainya. Bahkan, dalam kehidupan sehari-hari kampus, terdapat juga sebagian kecil mahasiswi - terlepas dari motivasi keagamaan atau tidak, yang menggunakan cadar.

Melalui survei yang disebar ke mahasiswa di atas, dapat dipahami bahwa kekhawatiran sekaligus asumsi awal yang menyatakan adanya pengaruh dari banyaknya aliran dan aksi keagamaan yang cenderung radikal terhadap mahasiswa di UIN Raden Mas Said dapat dianulir. Hal ini dapat dilihat dari pernyataan dan pendapat mahasiswa yang menunjukkan sikap moderasi beragama yang cukup tinggi. Hal tersebut juga menunjukkan bahwa mahasiswa masih berdaya tahan atau berketahanan untuk mencegah potensi masuknya paham intoleran eksklusif yang menjadi benih tumbuhnya paham radikalisme.

\section{Kesimpulan}

UIN Raden Mas Said Surakarta memang secara faktual dikelilingi oleh pergaulan ideologis yang perlu diwaspadai dengan upaya langkah pencegahan. Hal tersebut berpotensi memungkinkan adanya infiltrasi ajaran keagamaan eksklusif yang mengarah kepada intoleransi dan radikalisme. Namun, dalam penelitian ini ditemukan bahwa kekhawatiran itu tampaknya tidak terbukti, karena mahasiswa di kampus tersebut masih memiliki sikap moderat yang cukup tinggi. Dari sisi kelembagaan, temuan penelitian ini relevan pula dengan berbagai kebijakan yang sudah dilaksanakan oleh UIN Surakarta untuk memperkuat pemahaman Islam yang inklusif di kalangan sivitas akademika. Dibentuknya Rumah Moderasi Beragama, Pusat Studi Pancasila dan Kebangsaan (PSPK), Bilik Moderasi Islam dan Adab (BIMA), serta Pusat Pengkajian Masyarakat dan Pendidikan Islam Nusantara (PPM-PIN) yang mengkampanyekan Islam santun, menunjukkan sinergitas kebijakan kampus dengan ketahanan sikap inklusif mahasiswa dalam mempertahankan karakter beragama yang moderat.

\section{Referensi}

Abrori, Fajar. “Densus 88 Tangkap 6 Teroris Di Solo Terkait JAD Kendal.” Liputan6, 2020.

Ahyar, Muzayyin. "Membaca Gerakan Islam Radikal Dan Deradikalisasi Gerakan Islam." Walisongo: Jurnal Penelitian Sosial Keagamaan 23, no. 1 (2015): 1-26. https://doi.org/10.21580/ws.2015.23.1.220.

Azra, Azyumardi. “4. Distinguishing Indonesian Islam. Some Lessons to Learn.” In Islam in Indonesia: Contrasting Images and Interpretations, edited by Jajat Burhanuddin and Kees van Dijk, 63-74. Amsterdam: Amsterdam University Press, 2013. https://doi.org/10.1515/9789048516254-005/HTML.

Bahri, Samsul. "Perspektif Teori Struktural Fungsionalisme Tentang Ketahanan Sistem Pendidikan Pesantren.” MIQOT: Jurnal Ilmu-Ilmu Keislaman 40, no. 1 (2016): 88-105. https://doi.org/10.30821/miqot.v40i1.221.

Dirhantoro, Tito. "Ini Motif 7 Anak Yang Merusak Makam Di Solo, Kini Jadi Tersangka." Kompas.tv, 2021.

Fahri, Mohamad, and Ahmad Zainuri. "Moderasi Beragama Di Indonesia." Intizar 25, no. 2 (2019): 95-100. https://doi.org/10.19109/intizar.v25i2.5640. 
Fuadi, Moh Ashif, Fuad Hasyim, Muhammad Nur Kholis, Abraham Zakky Zulhazmi, and Rustam Ibrahim. "Strengthening Religious Moderation to Counter Radicalism at IAIN Surakarta." Al-Tahrir: Jurnal Pemikiran Islam 21, no. 02 (2021): 261-84. https://doi.org/10.21154/altahrir.v21i2.3102.

Jazuli, Ahmad. "Strategi Pencegahan Radikalisme Dalam Rangka Pemberantasan Tindak Pidana Terorisme." Jurnal Ilmiah KEBIJAKAN HUKUM 2, no. 10 (2016). https://doi.org/10.30641/kebijakan.2016.V10.197-209.

Jura, Demsy. "Religious Moderation: An Approach of Religious Life in Indonesia." Jurnal Inovasi Penelitian 1, no. 10 (2021). https://doi.org/10.47492/jip.v1i10.407.

LP2M IAIN Surakarta. "Pengumuman Pembagian Kelompok Dan Dosen Pembimbing Lapangan (DPL) KKN Kerso Darma 2021.” LP2M, 2021.

LPPM UNUSIA. “Islam Eksklusif Transnasional Merebak Di Kampus-Kampus Negeri.” Jakarta, 2019.

Maunah, Binti. "Pendidikan Dalam Perspektif Struktural Konflik." CENDEKIA: Journal of Education and Teaching 9, no. 1 (2016): 71. https://doi.org/10.30957/cendekia.v9i1.53.

Nur, Afrizal, and Mukhlis Lubis. "Konsep Wasathiyah Dalam Al-Quran; (Studi Komparatif Antara Tafsir Al-Tahrîr Wa at-Tanwîr Dan Aisar at-Tafâsîr)." An-Nur 4, no. 2 (2015): 20525. http://ejournal.uin-suska.ac.id/index.php/Annur/article/view/2062/1401.

Parsons, Talcott. The Structure of Social Action. New York N.Y.: McGraw-Hill Book Company, 1937.

Pikoli, Wiliansyah, Yosafat Hermawan Trinugraha, and Yuhastina Yuhastina. "Peran Tokoh Agama Islam, Hindu, Dan Kristen Dalam Menjaga Kerukunan Beragama Di Desa Banuroja, Gorontalo." Al-Adabiya: Jurnal Kebudayaan Dan Keagamaan 16, no. 1 (2021): 79-95. https://doi.org/10.37680/adabiya.v16i1.827.

Poerwadarminta. Kamus Besar Bahasa Indonesia. Jakarta: Balai Pustaka, 1990.

Purwanto, Yedi, Qowaid, Lisa'diyah Ma'rifataini, and Ridwan Fauzi. "Internalisasi Nilai Moderasi Melalui Pendidikan Agama Islam Di Perguruan Tinggi Umum." EDUKASI: Jurnal Penelitian Pendidikan Agama Dan Keagamaan 17, no. 2 (2019): 110-24. https://doi.org/10.32729/edukasi.v17i2.605.

Rahman, Ichsan Kholif. "Bentrok Usai Demo Protes Gus Muwafiq, PCNU Solo: Malu! Mau Sampai Kapan?" Solopos, 2019.

Rosyada, Dede. "Pendidikan Multikultural Di Indonesia Sebuah Pandangan Konsepsional." SOSIO DIDAKTIKA: Social Science Education Journal 1, no. 1 (2014). https://doi.org/10.15408/sd.v1i1.1200.

Santoso, Audrey. "Polisi: Pelaku Bom Kartasura Sukoharjo Terpapar Paham ISIS." Detik.com, 2019.

Saptoyo, Rosy Dewi Arianti. "Hari Ini Dalam Sejarah: Teroris Noordin M Top Tewas Di Solo." Kompas.com, 2021.

Satriawan, Yudha. "Bedah Buku Di Kampus IAIN Surakarta Didemo Ratusan Anggota Ormas Islam.” VOA Indonesia, 2017.

Setyawan, Agus. "Dakwah Yang Menyelamatkan: Memaknai Ulang Hakikat Dan Tujuan Da'wah Islamiyah." Al-Adabiya: Jurnal Kebudayaan Dan Keagamaan 15, no. 02 (2020): 189-99. https://doi.org/10.37680/adabiya.v15i02.487.

Shihab, M. Quraish. Wasathiyah; Wawasan Islam Tentang Moderasi Beragama. Tangerang: 
Lentera Hati, 2019.

Suharto, Toto, and Ja'far Assagaf. "Membendung Arus Paham Keagamaan Radikal Di Kalangan Mahasiswa PTKIN.” Al-Tahrir: Jurnal Pemikiran Islam 14, no. 1 (2014): 157. https://doi.org/10.21154/al-tahrir.v14i1.72.

Syawaludin, Mohammad. "Alasan Talcott Parsons Tentang Pentingnya Pendidikan Kultur." Ijtimaiyya 7, no. 1 (2014): 919-28. https://doi.org/10.24042/ijpmi.v7i2.929.

Tim Penyusun Kementerian Agama. Moderasi Beragama. Jakarta: Badan Litbang dan Diklat Kementerian Agama RI, 2019.

Turama, Akhmad Rizqi. "Formulasi Teori Fungsionalisme Struktural Talcott Parsons." EUFONI : Journal of Language, Literary and Cultural Studies 2, no. 2 (2018): 58-69. https://doi.org/10.32493/efn.v2i2.5178.

Widodo, M. Hafidh. "Ideologi Takfiri Muhammad Al-Maqdisi : Memahami Hubungan Beragama Dan Bernegara Perspektif Maqāshid Asy-Syarī'Ah.” Living Islam 1, no. 2 (2018). https://doi.org/10.14421/lijid.v1i2.1709.

Zuhdi, Muhammad Harfin. "Radikalisme Agama Dan Upaya Deradikalisasi Pemahaman Keagamaan." AKADEMIKA 22, no. 1 (2017): 92-105. $\mathrm{https:// \textrm {e }}$ journal.metrouniv.ac.id/index.php/akademika/article/view/568. 